\title{
Association between Common Space Occupancy and Spatial Configuration in Japanese Nursing Home
}

\author{
Lin Bai, Satoshi Nasu \\ Department of Architecture, \\ School of Environment and Society, \\ Tokyo Institute of Technology, Japan \\ bailinkylin@gmail.com
}

\begin{abstract}
This paper explores the association between common facility space occupancy and spatial configuration and aims to have higher space occupancy by spatial design. The spatial configuration includes geometric metrics and topologic metrics from Space syntax theory. The association between space occupancy and spatial configuration in twelve nursing homes is evaluated using the multiple linear regression model. The results show that spatial integration, connectivity, and area size are significant factors to space occupancy correlation. Therefore, allocating space with higher spatial integration, more connectivity, and the large area size are three effective ways to increase space occupancy in Japanese nursing homes.
\end{abstract}

Keywords: Space syntax; Space occupancy; Spatial configuration; Nursing home.

eISSN 2514-751X @ 2019. The Authors. Published for AMER, ABRA \& cE-Bs by E-International Publishing House, Ltd., UK. This is an open-access article under the CC BY-NC-ND license (http://creativecommons.org/licenses/bync-nd/4.0/). Peer-review under responsibility of AMER (Association of Malaysian Environment-Behaviour Researchers), ABRA (Association of Behavioural Researchers on Asians) and CE-Bs (Centre for EnvironmentBehaviour Studies), Faculty of Architecture, Planning \& Surveying, Universiti Teknologi MARA, Malaysia.

DOI: https://doi.org/10.21834/aje-bs.v4i14.352 


\section{Introduction}

\subsection{Background and Research Purpose}

The common facilities in a nursing home can influence residents' social life (Byoung-Suk, William, Angela, 1998), which would affect their life satisfaction (Park, 2009), and quality of life(Candace et al.,2012).

However, the space occupancy of the common facilities in Japanese nursing homes is low, especially in the public and semi-public areas. Investigation shows residents spent about over $90 \%$ of the time a day in the care unit where they live, and only spent $4 \%$ to $10 \%$ in the hall, lobby, community space, physical training room, etc. public area(Kanki, Takada, Miura, 2005a; Ishibashi, Ishii, Miura, 2015).

The longer staying time of residents in the care unit and low occupancy of the space in the common facilities bring the risk that the residents close themselves in the small unit and affect their social life. Therefore, it is essential to promote the use of space in common facilities to enhance residents' social exchange (Kanki, Takada, Miura, 2005b).

There have been growing interests in applying Space syntax theory (SS theory) to analyze the relationship between people's social activity and the spatial configuration in urban design and public buildings (Takano, 2012). From the year of 2000, there are many use cases in commercial facilities, libraries, and museums. However, the elderly's movement and utilization in the space of the nursing home may differ from general people in public facilities because of the possible slow space recognition of elderly and defined care service. The method and application of SS theory for general peoples' space recognition and utilization may not always apply to elderly residents in the nursing home.

In this article we verify the correlation between SS spatial metrics and space occupancy in Japanese nursing home common facilities, to explore their association, and to provide a reference on the spatial design from the perspective of having higher space occupancy.

\subsection{Literature Review}

Common space design is a study of concern in Japanese nursing home. There are some reports so far to verify the utilization and importance of common space to resident social life. These researches include the study of the need for common facilities in the nursing home by Inoue (1990), the behavior observation for over fifty residents in three nursing homes by Kato(2007), and the problems in current nursing home common space designing that some care functions which should originally be performed in the common facility space were actually packed into private room(Mori S., 2004), etc.

There are also several studies about spatial configuration and its relation to social activity (Congsi \& Gesine, 2015). Alan's study on the effect on the spatial configuration to communication patterns and people's movement is a typical example (Alan, Jake \& Laura, 1997). Besides, Turner verified the importance of spatial features in people's use of space (Turner, Doxa, Sullivan \& Penn, 2001), Dursun and Saglamer concluded that distinctive characteristics of societies exist within spatial systems by verified the association between social characteristics and space (Dursun \& Saglamer, 2003).

About spatial configuration and social activities in Japanese nursing home, Kang S. 
studied the space in four nursing home common facilities and concluded to widen facility space and front hall to secure communication among residents (Kang, 2012). Murakami S. investigated the basic elements in nursing home resident daily life, proposed a model in common space plan design (Murakami, 2011). Bai L. analyzed the changes of common space spatial configuration in the past 35 years for space area size (Bai, Nasu, 2018).

However, the studies on nursing home common facility spatial configuration, especially the quantitive association with the resident's social activity are still very limited. So far there is no report founded on the study of the quantitive association between common facility spatial configuration and space utilization for the common facilities in Japanese nursing home.

\section{Datasets and Method}

\subsection{Common Space in Japanese Nursing Home}

There are three main types of nursing homes in Japan; they are intensive care nursing home, private residential home, and elderly housing with support services. Among them, the Japanese government found the intensive care nursing home, which is the main elderly facility. This article focuses on this type of nursing home; hereinafter referred to as a nursing home.

Historically, the nursing home has transited from large-scale care type to unit care with the regulation by the Ministry of Health, Labour and Welfare in 2002 Note 1). There are shared space and personal space in unit care nursing home. The shared space includes public area mainly for social community service and the semi-public area. The personal space includes semi-private area such as living space and private area such as private room as shown in Figure 1.

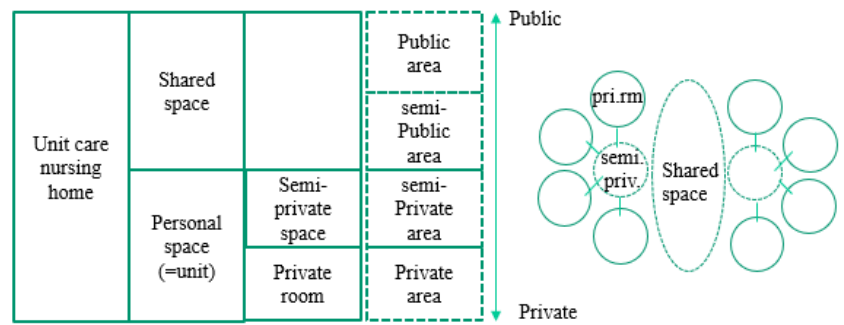

Figure 1: Common space in Japanese nursing home (Source: MHLW,2015(left), Mori, Inoue, Taniguchi,2003(right), translated by author)

The common space in this article means the public and semi-public area which mainly includes the community space, physical training room, clubhouse, care and service station, restaurant, and dining room, as shown in Table 1. 
Bai, L., \& Nasu, S. / Asian Journal of Environment-Behaviour Studies (ajE-Bs), 4(14) Sep / Dec 2019 (pp.1-20)

Table 1: Common space classification in Japanese nursing home

\begin{tabular}{cll}
\hline Symbol & Space category & Example \\
\hline ENH & Public & Entrance hall, lobby \\
DRM & Semi-public & Restaurant, dining room \\
PTR & Semi-public & Rehabilitee room, club room, clubhouse, physical \\
& & training room \\
MTR & Semi-public & Multiple purpose room, hobby room, game room, etc. \\
SST & Semi-public, semi-private & Care station, service station \\
CMS & Public & Community room, community space \\
DSR & Public, semi-public & Daily service room \\
\hline
\end{tabular}

(Source: Created by author)

\subsection{Factors Affecting Common Space Occupancy and Limitations of the Research}

There are several factors which may affect the occupancy of space in common facilities; they can be individual voluntary, human administrative, environmental, and spatial configuration.

The individual voluntary factors may include and individual preference, previous and living experiences, culture habits, interpersonal relationships, etc. The human administrative factors include scheduled activities, organized events like festival party, etc. Environmental factors can be equipment like air conditioning, furniture arrangement, room lighting, and decoration.

However, in this article, we don't consider the effect by the social and cultural aspects of the residents, and the administrative environment. Here we only take into account the space configuration, that is, the spatial configuration which is also the inherent factor of space; it can't be changed as long as space is created.

Space syntax theory provides a set of techniques to describe spatial configuration based on space topological structure. The theory makes it possible to develop a set of supposition about how space networks relate to the social, economic and cognitive aspects, and how they are affected (Hillier et al., 2007). It has been getting used broadly since the beginning and has been generally accepted as an appropriate means in spatial configuration comparative study (Brown, 1986). However, the theory ignores many space geometric details, such as distance, shape, and precision position (Chaeshin, 2009).

In this article, except the metrics from SS theory (also called topologic metrics in this article), we think space geometrical characteristics such as area size, shape, the physical distance could also affect the space occupancy. Because in common sense, the larger and the nearer to space, the more people tend to use. Therefore, we also consider the geometric metrics, like area size, proximity, and shape in this research.

Therefore, the spatial configuration that potentially relates to space occupancy in this article includes:

- Geometrical metrics, like

- Space area size

- Space shape: circle, square, rectangle, triangle, etc.

- The proximity(physical distance)

- The Space syntax topological metrics

- Spatial connectivity

- Spatial accessibility 
- Spatial integration

\subsection{Common Space Occupancy}

The opportunity for social exchange would increase when residents stay in the common space longer. Compared to the specific behavior in space such as chatting, playing, reading, meditating, the stay time is more fundamental in social exchange. Therefore, instead of a particular behavior, we take the stay time as the indicator of space occupancy in this study.

The space occupancy in this article means the proportion of time that space is occupied during a specified period a day. We define it as the percentage of time averagely one resident spent in space to the total observation duration (8:00 am 6:00 pm). Then, we performed on-site survey and interview of nursing home staffs, to record the number of residents staying in the common facility space in each 30 minutes time interval, and to calculate the occupancy by

$$
O C P(\%)=\frac{\sum(S U M * T I M)}{\text { Total observed residents } * \text { DUR }(\text { mins })}
$$

where the NUM is the number of residents staying in a space; TIM is the observation time interval, 30 mins; DUR is observation period, 600 mins from 8:00 am to 6:00 pm.

\subsection{Space Syntax Theory and Method}

Space syntax theory uses different approaches to evaluate the spatial configuration (Varoudis, 2013). One approach is the convex map method which uses vertical boundaries to convert 3-D space to the 2-D convex map (polygon)(Peonies, 2002) and establishes a connection based on the availability of direct access. Because of this "fat" nature of the convex, this method is best suited for defining building interior space (Peiman, 2014) and is applied in this research for the nursing home.

Based on the space function, each space in a nursing home is presented by the least number of the convex map. The wall, any partition that separates space, is taken as a boundary while doors and openings are connection points. For multi-story buildings, according to the allocation of space, elevators and staircases are connection points.

The spatial connectivity $(\mathrm{CNN})$ of a space specifies the neighbor space $(\mathrm{N})$ directly connects to it. The space with high connectivity owns more connections to others; the space with less connectivity is relatively isolated.

$$
C N N=N
$$

The depth (DEP) is the change steps(S) from specified space to others; it is the number of steps to turn over, not the actual distance. The depth between immediate neighbors is one. The higher the depth of the specified space, the worse the accessibility. The total depth (TDP) of a space is the sum of the depths from all others, and the mean depth(MDP) is the ratio of the total depth to the total number of spaces by minus one(Hillier, 1984, pp.108).

$$
\begin{gathered}
D E P=S \\
T D P=\sum_{k=1}^{n}(D E P k * k) \\
M D P=\frac{\sum_{k=1}^{n}(D E P k * k)}{n-1}
\end{gathered}
$$

where $\mathrm{n}$ is the number of total spaces. 
Figure 2 shows the example of connectivity (DEP), total depth (TDP), and mean $\operatorname{depth}(\mathrm{MDP})$ of space $A \sim$ space $F$.

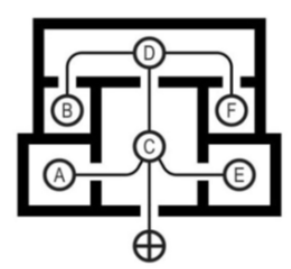

A

Convex spaces

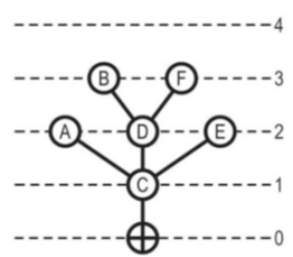

$\operatorname{CNN}(A)=1, \operatorname{TDP}(A)=1+2+2+3+3=11, \operatorname{MDP}(A)=11 /(6-1)$ $\operatorname{CNN}(B)=1, \operatorname{TDP}(B)=1+2+2+3+3=11, \operatorname{MDP}(B)=11 /(6-1)$ $\mathrm{CNN}(\mathrm{C})=3, \operatorname{TDP}(\mathrm{C})=1+1+1+2+2=7, \operatorname{MDP}(\mathrm{C})=7 /(6-1)$ $\operatorname{CNN}(D)=3, \operatorname{TDP}(D)=1+1+1+2+2=7, \operatorname{MDP}(D)=7 /(6-1)$

$\mathrm{CNN}(E)=1, \operatorname{TDP}(E)=1+2+2+3+3=11, \operatorname{MDP}(E)=11 /(6-1)$ $\operatorname{CNN}(F)=1, \operatorname{TDP}(F)=1+2+2+3+3=11, \operatorname{MDP}(F)=11 /(6-1)$

B

Connectivity, Total depth, Mean depth

\section{Justified access graph}

Figure 2: Connectivity, total depth, and mean depth

(Source: Michael \& Michael, 2013, p3, modified by author)

The spatial integration (INT) describes the average depth of specified space to all others in one system as a nursing home building. It is also regarded as the index of accessibility. If the integration of space is high, this space is well integrated into the system. If the mean integration of all spaces in a system is high, it means that all the spaces are highly connected and integrated. In SS theory, the formula to calculate integration is:

$$
I N T=\frac{n\left\{\log 2\left(\frac{n+2}{3}\right)-1\right\}+1}{(M D P-1)(n-1)}
$$

\subsection{Common Space Occupancy and Spatial Configuration Regression Analysis}

The multiple linear regression analysis attempts to identify the relationship between two or more independent variables and a dependent variable by fitting a linear equation to observed data. This method meets the need to find the association between space occupancy and spatial configuration, and to recognize the significant spatial metrics that relate to space occupancy. We use this method and the IBM SPSS, data statistics tool, in this research (IBM Corp., 2016).

\section{Result}

\subsection{Common Space Occupancy Survey}

\section{(1) Survey Site Consideration}

We select twelve nursing homes in Tokyo and Yokohama area for the on-site survey. The survey started on Sep. 6, 2017 to Dec. 20, 2017, involving 1070 nursing home residents. The conditions considered during the study include:

1. The room temperature is almost well-conditioned. There is no much difference with most of the other Japanese nursing homes.

2. The health status of residents' nursing care level and dementia should be within the 
average level of other Japanese nursing homes.

3. Exclude the space occupancy data for the on-purpose event.

Table 2 lists the percentage of residents with a dementia disease, the residents of different nursing care level Note 2), and, the result from the survey by the Ministry of Health, Labour, and Welfare. In Table 2, the residents of nursing care level $1 \sim$ level 4 in our survey are $4.9 \%, 10.0 \%, 28.1 \%$, and $81.9 \%$ respectively, which are the same level as all Japanese nursing home average of $2.2 \%, 6.1 \%, 23.0 \%$, and 68.6\% in Sep. 2016(MHLW,2017,Fig. 4.4).

Table 2: The list of nursing homes surveyed

\begin{tabular}{|c|c|c|c|c|c|c|c|c|c|}
\hline $\begin{array}{l}\mathrm{NH} \\
\mathrm{ID}^{* 1}\end{array}$ & $\begin{array}{l}\text { Care } \\
\text { type* } \\
2\end{array}$ & $\begin{array}{l}\text { Cap } \\
\text { acity }\end{array}$ & $\begin{array}{l}\text { Deme } \\
\text { ntia,\% }\end{array}$ & $\begin{array}{r}\text { Nursing } \\
\text { care level } \\
1, \%\end{array}$ & $\begin{array}{r}\text { Nursing } \\
\text { care level } \\
2, \%\end{array}$ & $\begin{array}{r}\text { Nursing } \\
\text { care level } \\
3, \%\end{array}$ & $\begin{array}{r}\text { Nursing } \\
\text { care >= } \\
\text { level } 4, \%\end{array}$ & $\begin{array}{l}\text { Site area, } \\
\mathrm{m}^{2}\end{array}$ & $\begin{array}{l}\text { Total } \\
\text { loor } \\
\text { area, m² }\end{array}$ \\
\hline 1 & L & 66 & 80 & 7.6 & 7.6 & 16.7 & $\mathrm{n} / \mathrm{a}$ & 21,205 & 3,225 \\
\hline 2 & U & 87 & 80 & n/a & 4.6 & 20.7 & n/a & $2,852^{* 3}$ & $3,599^{* 3}$ \\
\hline 3 & L & 100 & 85 & n/a & n/a & 100.0 & n/a & 16,606 & 6,150 \\
\hline 4 & $L$ & 72 & & 2.8 & 8.3 & 16.7 & 72.2 & 11,790 & 4,989 \\
\hline 5 & $L$ & 63 & 90 & $\mathrm{n} / \mathrm{a}$ & 11.1 & 12.7 & $\mathrm{n} / \mathrm{a}$ & 6,693 & 3,904 \\
\hline 6 & L & 60 & 50 & $\mathrm{n} / \mathrm{a}$ & 1.7 & 6.7 & 91.7 & 2,200 & 3,288 \\
\hline 7 & $L$ & 52 & 85 & $\mathrm{n} / \mathrm{a}$ & 13.5 & 42.3 & $\mathrm{n} / \mathrm{a}$ & 4,603 & 6,636 \\
\hline 8 & $L$ & 50 & 80 & $\mathrm{n} / \mathrm{a}$ & $\mathrm{n} / \mathrm{a}$ & 14.0 & $\mathrm{n} / \mathrm{a}$ & 9,441 & 8,145 \\
\hline 9 & L & 80 & 70 & 1.3 & 3.8 & n/a & $n / a$ & 3,895 & 5,517 \\
\hline 10 & U & 54 & 20 & $\mathrm{n} / \mathrm{a}$ & $\mathrm{n} / \mathrm{a}$ & $\mathrm{n} / \mathrm{a}$ & $\mathrm{n} / \mathrm{a}$ & 5,991 & 3,531 \\
\hline 11 & U & 96 & 80 & 4.2 & 29.2 & $\mathrm{n} / \mathrm{a}$ & $\mathrm{n} / \mathrm{a}$ & 2,670 & 4,036 \\
\hline 12 & U & 140 & 85 & 8.6 & 10.7 & 23.6 & $\mathrm{n} / \mathrm{a}$ & 4,006 & 7,989 \\
\hline Ave. & & & $73.2 \%$ & 4.9 & 10.0 & 28.1 & 81.9 & & \\
\hline $\mathrm{H} 28^{*}$ & & & $\begin{array}{r}74.9 \\
\%\end{array}$ & 2.2 & 6.1 & 23.0 & 68.6 & & \\
\hline
\end{tabular}

*1 NHID, nursing home ID; *2, L - large scale care type, U - unit care type; *3, Estimated from floor plan; *4 The average of the 2016 year in all Japanese intensive care nursing home, refer to MHLW(2017).

(Source: Created by author)

The residents with dementia are $73.2 \%$ in our survey(Figure 3), which is also the same level as all Japanese nursing home of 74.9\%(MHLW 2017, Fig. 4.2).

Therefore, the twelve surveyed nursing homes in this article can be a representative of Japanese nursing homes from the aspect of the residents' health condition.

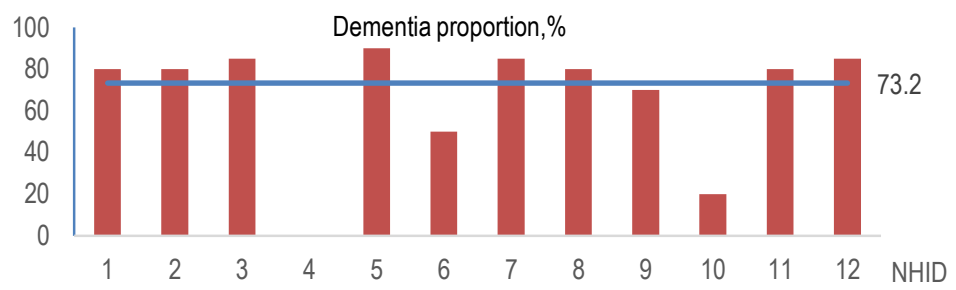

Figure 3: Percentage of residents with dementia in surveyed nursing homes

(Source: Created by author) 
(2) Occupancy Survey Result

Table 3 and Figure 4 are the survey results, where the blank in the table means no such common space or no occupancy data.

The average occupancy of the entrance hall in the surveyed nursing homes is $3.92 \%$, the dining room is $10.18 \%$, the community space is $1.52 \%$, the physical training room is $0.77 \%$.

The occupancy in the entrance hall, community space, and physical training room sums to $6.21 \%$, which is consistent with the result by Kanki et al. in 2005 that the time staying in hall, lobby, community space, physical training room, etc. common facilities was $4 \%$ to less than $10 \%$ (Kanki et al., 2005b).

Besides, comparing the Figure 4 and Figure 3, it shows that the difference in residents' health condition doesn't affect the space occupancy rate too much. For example, in Figure 3 , the residents with dementia in the nursing home ID 10 is $20 \%$, which is much less than the average of $73.2 \%$. However, in Figure 4, the space occupancy of nursing home ID 10 is $15.37 \%$, which is close to all 12 nursing home average of $18.02 \%$. Therefore, as the initial research stage, we don't detail the utilization difference by nursing home residents' health characteristics.

Table 3: Nursing home space occupancy survey result, $\%$

\begin{tabular}{rllllllll}
\hline NHID & ENH & DRM & PTR & MPR & SST & CMS & DSR & Total \\
\hline 1 & 9.70 & $22.73^{* 1}$ & 0.45 & & & 1.21 & & 34.20 \\
2 & 1.49 & 6.90 & & & 0.23 & 0.86 & & 10.06 \\
3 & 3.15 & 9.20 & 1.40 & & & 1.00 & 1.60 & 16.35 \\
4 & 2.08 & $18.06^{* 2}$ & 1.39 & 2.78 & & 6.25 & & 30.56 \\
5 & 1.27 & 15.87 & 0.63 & & & 1.27 & & 19.05 \\
6 & 5.50 & 7.50 & 0.33 & 0.50 & 0.50 & 0.50 & 0.83 & 15.67 \\
7 & 8.37 & 7.69 & 0.38 & 0.38 & & 1.54 & 0.96 & 19.33 \\
8 & 6.00 & 0.60 & & & 0.60 & 2.00 & 4.00 & 13.20 \\
9 & 0.88 & 13.44 & 1.25 & 0.75 & 0.50 & 0.19 & 0.50 & 17.50 \\
10 & 3.52 & 5.56 & & 0.37 & 0.56 & 0.37 & 4.44 & 15.37 \\
11 & 3.75 & 14.06 & 0.73 & & 0.73 & 0.94 & & 20.21 \\
12 & 1.36 & 0.57 & 0.36 & & 0.07 & 2.14 & & 4.71 \\
Ave & 3.92 & 10.18 & 0.77 & 0.89 & 0.46 & 1.52 & 2.06 & 18.02 \\
\hline
\end{tabular}

*1,2 The two occupancy data is much higher than others, the reason is there was a special event held. We remove this data for the following analysis.

(Source: Created by author)

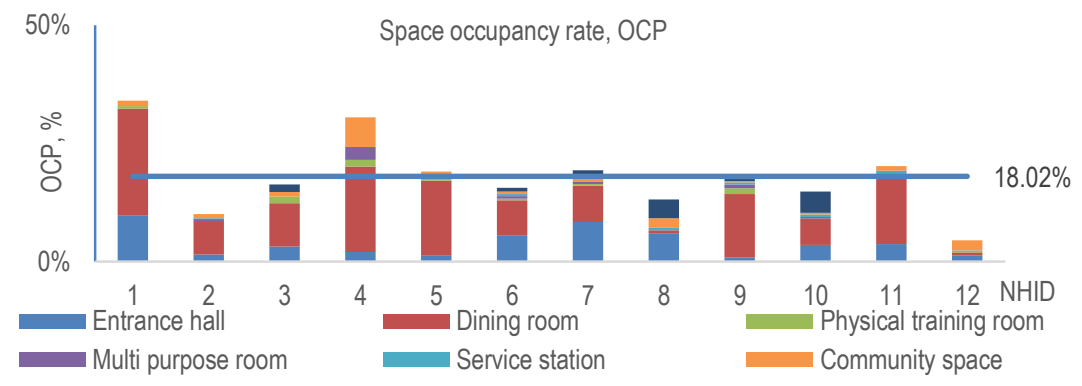

Figure 4: Common space occupancy survey result of 12 nursing homes 
(Source: Created by author)

\subsection{Result of SS Spatial Metrics of Common Space}

The floor plan of each nursing home is scanned and converted to AutoCAD file, which then imports to DepthMapX, the SS analysis tool (Varoudis T., 2012). Based on the method in 2.4 , for each space in a nursing home, we create the convex map and calculate the spatial integration, spatial connectivity, mean depth, and total depth.

Figure 5 is a result example. The left is the floor plan, middle and right are the convex map, connectivity, and the spatial integration which colored based on its value, the thick to thin color represents the high value of well-integrated location to the poor.
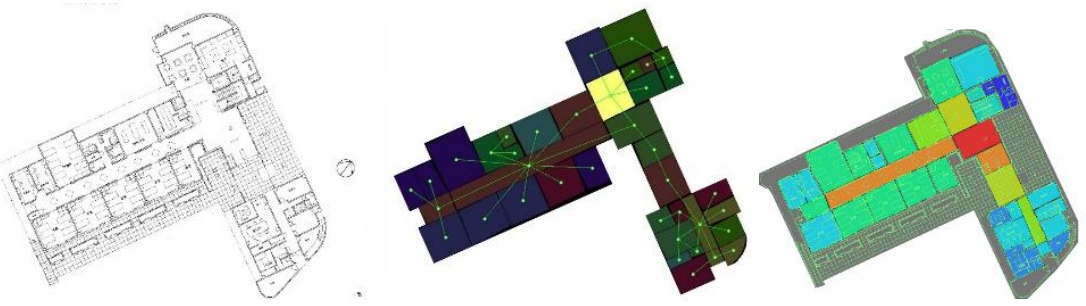

Figure 5: Floor plans (left), convex map, connectivity (middle), and spatial integration (right) sample result by DepthMapX tool (Source: Created by author)

Table 4 lists the SS spatial integration and surveyed occupancy for common space in the 12 nursing homes.

Table 4: Spatial integration and surveyed occupancy in 12 nursing homes

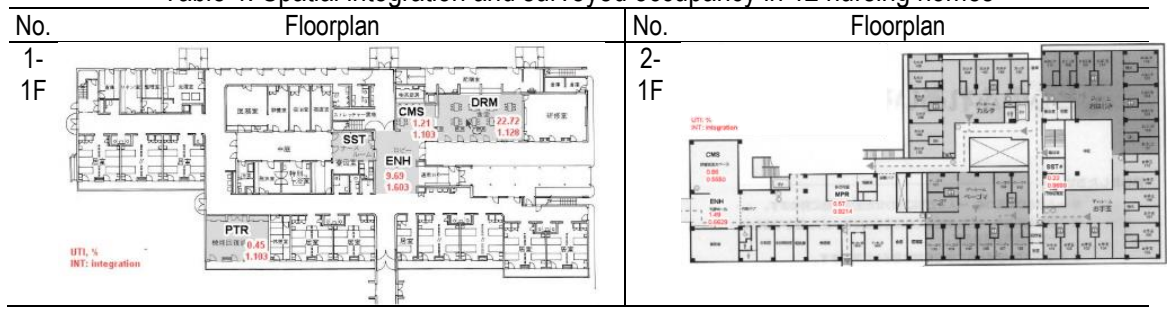


Bai, L., \& Nasu, S. / Asian Journal of Environment-Behaviour Studies (ajE-Bs), 4(14) Sep / Dec 2019 (pp.1-20)

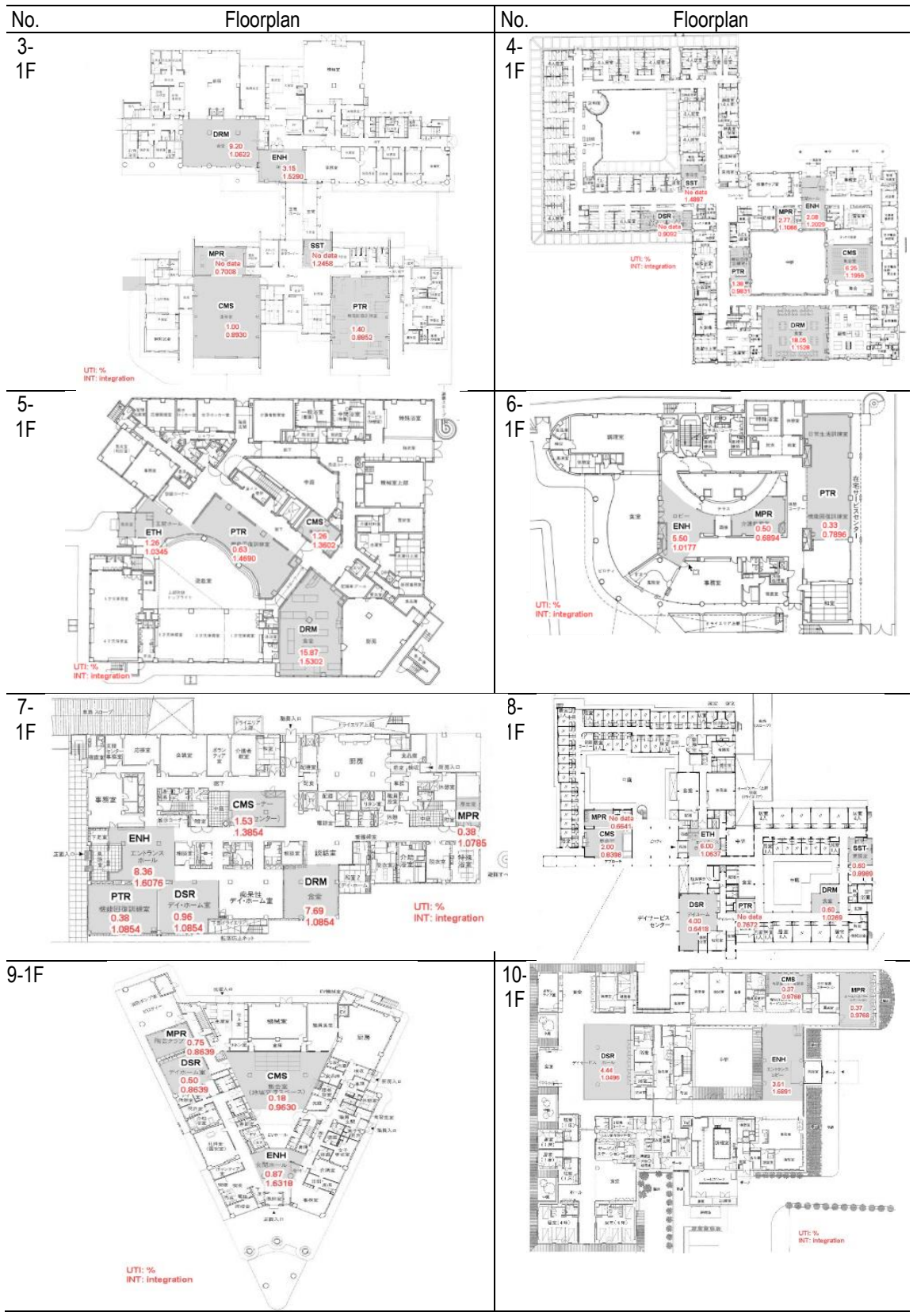


Bai, L., \& Nasu, S. / Asian Journal of Environment-Behaviour Studies (ajE-Bs), 4(14) Sep / Dec 2019 (pp.1-20)

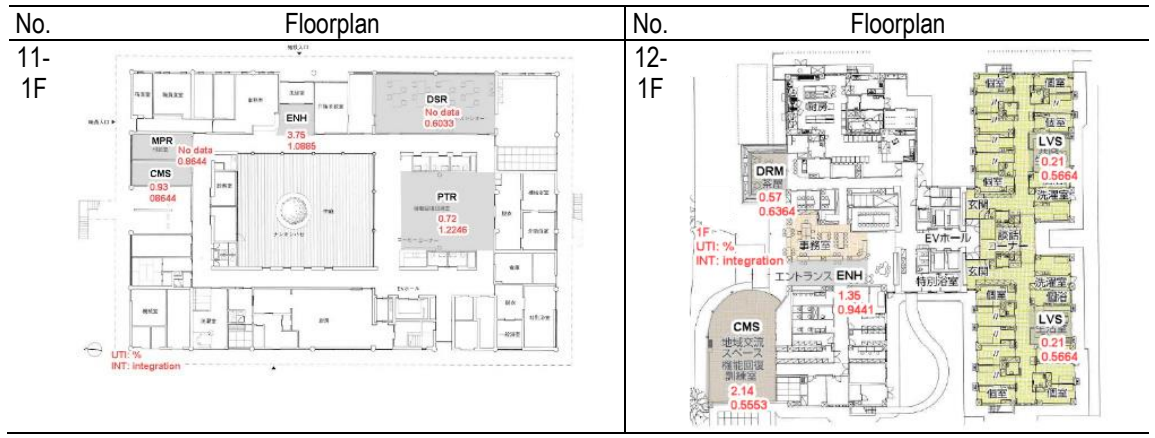

(Source: Created by author)

\subsection{Common Space Geometrical Metrics}

We use the AutoCAD tool to measure the area size of each space.

For space shape, we also investigated the ratio of length in a vertical direction to horizontal (VHR) in the 2-D floor plan, as shown in Figure 6.

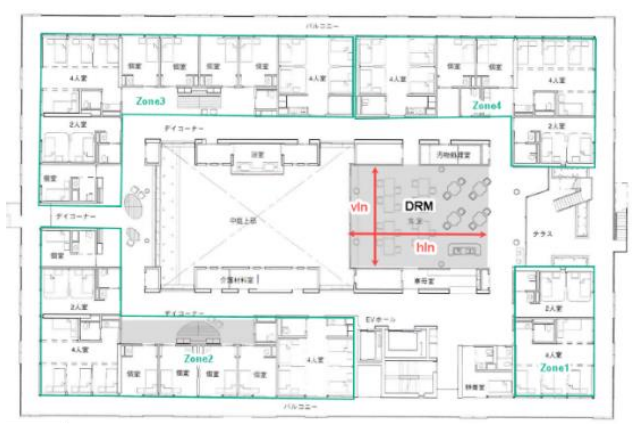

Figure 6: VHR, the ratio of vertical to horizontal (Source: Created by author)

For the physical distance from the resident care unit to common facilities, we investigated the proximity (PRX), which is the average distance from the care unit zone. Figure 7 is the result. 


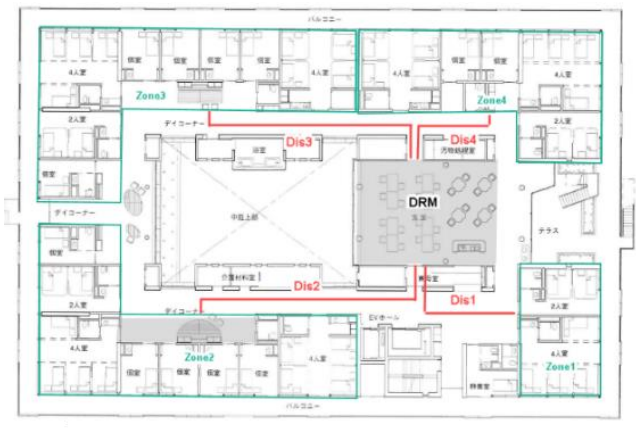

Figure 7: VHR, the ratio of vertical to horizontal (Source: Created by author)

Table 5 lists the geometrical metric result of the twelve nursing homes.

Table 5: Common space occupancy and spatial configuration data

\begin{tabular}{|c|c|c|c|c|c|c|c|c|c|}
\hline $\begin{array}{r}\text { Common } \\
\text { space } \\
\end{array}$ & NHID & $\begin{array}{l}\text { ARE, } \\
m^{2} / p\end{array}$ & INT & CNN & MDP & TDP & VHR & PRX & OCP, \% \\
\hline \multirow[t]{12}{*}{ ENH } & 1 & 0.70 & 1.603010 & 6.0 & 2.979170 & 143.00 & 1.45 & 42.51 & 9.70 \\
\hline & 2 & 0.30 & 0.662910 & 3.0 & 6.054545 & 333.00 & 0.70 & 58.43 & 1.49 \\
\hline & 3 & 0.27 & 1.5290344 & 6.0 & 2.914290 & 102.00 & 0.70 & 6.71 & 3.15 \\
\hline & 4 & 0.38 & 1.2029306 & 5.0 & 2.8333333 & 218.00 & 1.82 & 44.06 & 2.08 \\
\hline & 5 & 0.09 & 1.034520 & 3.0 & 3.448280 & 100.00 & 0.54 & 27.00 & 1.27 \\
\hline & 6 & 0.79 & 1.017796 & 6.0 & 3.976740 & 43.00 & 1.15 & 12.30 & 5.50 \\
\hline & 7 & 0.58 & 1.607630 & 8.0 & 3.038460 & 158.00 & 0.85 & 24.30 & 8.37 \\
\hline & 8 & 0.18 & 1.063750 & 3.0 & 4.486110 & 323.00 & 0.86 & 36.77 & 6.00 \\
\hline & 9 & 0.34 & 1.631850 & 3.0 & 2.800000 & 112.00 & 0.67 & 3.24 & 0.88 \\
\hline & 10 & 0.95 & 1.689170 & 3.0 & 2.548390 & 79.00 & 1.79 & 21.00 & 3.52 \\
\hline & 11 & 0.30 & 1.0885593 & 2.0 & 3.1600001 & 79.00 & 0.95 & 26.25 & 3.75 \\
\hline & 12 & 0.25 & 0.944118 & 2.0 & 4.076920 & 159.00 & 0.33 & 39.69 & 1.36 \\
\hline \multirow[t]{12}{*}{ DRM } & 1 & 0.81 & 1.128040 & 4.0 & 3.812500 & 183.0 & 0.55 & 56.29 & \\
\hline & 2 & 2.40 & 0.70126456 & 3.0 & 5.5999999 & 280.0 & 1.00 & 4.47 & 6.90 \\
\hline & 3 & 1.00 & 1.0622765 & 2.0 & 3.6388888 & 131.0 & 0.61 & 14.75 & 9.20 \\
\hline & 4 & 1.48 & 1.1528085 & 4.0 & 3.9473684 & 225.0 & 0.78 & 58.05 & \\
\hline & 5 & 0.61 & 1.530230 & 3.0 & 2.655170 & 77.0 & 1.71 & 10.44 & 15.87 \\
\hline & 6 & 1.52 & 1.255640 & 2.0 & 2.833333 & 68.0 & 0.61 & 30.65 & 7.50 \\
\hline & 7 & 0.73 & 1.085410 & 1.0 & 4.019230 & 209.0 & 0.97 & 9.18 & 7.69 \\
\hline & 8 & 0.23 & 1.026930 & 2.0 & 4.611110 & 332.0 & 0.57 & 34.34 & 0.60 \\
\hline & 9 & 2.05 & 1.195890 & 3.0 & 3.314290 & 116.0 & 0.74 & 26.19 & 13.44 \\
\hline & 10 & 1.45 & 0.95512819 & 1.0 & 3.0555556 & 55.0 & 1.00 & 6.13 & 5.56 \\
\hline & 11 & 1.14 & 1.474182 & 3.0 & 2.7741935 & 86.0 & 0.74 & 17.76 & 14.06 \\
\hline & 12 & 0.26 & 0.636484 & 1.0 & 5.564100 & 217.0 & 1.29 & 49.95 & 0.57 \\
\hline \multirow[t]{6}{*}{ PTR } & 1 & 0.54 & 1.103520 & 1.0 & 3.875000 & 186.0 & 0.75 & 48.97 & 0.45 \\
\hline & $\begin{array}{l}2 \\
3\end{array}$ & 104 & 0885230 & 40 & 41666665 & 1190 & 055 & 3800 & 140 \\
\hline & 4 & $\begin{array}{l}1.04 \\
0.56\end{array}$ & 0.983106 & $\begin{array}{l}4.0 \\
2.0\end{array}$ & $\begin{array}{l}4.1000005 \\
4.456141\end{array}$ & 254.0 & 2.30 & 40.30 & $\begin{array}{l}1.40 \\
1.39\end{array}$ \\
\hline & 5 & 0.36 & 1.469020 & 2.0 & 2.724140 & 79.0 & 0.93 & 14.40 & 0.63 \\
\hline & 6 & 1.26 & 0.789687 & 1.0 & 4.837210 & 59.0 & 2.71 & 20.50 & 0.33 \\
\hline & 7 & 0.84 & 1.085410 & 1.0 & 4.019230 & 209.0 & 0.71 & 36.72 & 0.38 \\
\hline
\end{tabular}


Bai, L., \& Nasu, S. / Asian Journal of Environment-Behaviour Studies (ajE-Bs), 4(14) Sep / Dec 2019 (pp.1-20)

\begin{tabular}{|c|c|c|c|c|c|c|c|c|c|}
\hline \multirow[t]{5}{*}{ space } & NHID & $\begin{array}{l}\text { ARE, } \\
m^{2} / p\end{array}$ & INT & CNN & MDP & TDP & VHR & PRX & OCP, \% \\
\hline & 8 & 0.12 & 0.767246 & 2.0 & 5.833330 & 420.0 & 0.71 & 55.29 & \\
\hline & 9 & 0.36 & 1.030500 & 3.0 & 3.685710 & 129.0 & 2.00 & 25.38 & 1.25 \\
\hline & 11 & 0.73 & 1.2246293 & 2.0 & 2.9200001 & 73.0 & 0.83 & 10.50 & 0.73 \\
\hline & 12 & 0.09 & 0.717967 & 1.0 & 5.000000 & 190.0 & 0.90 & 5.40 & 0.36 \\
\hline \multirow[t]{11}{*}{ MPR } & 1 & & & & & & & & \\
\hline & 2 & 0.16 & 0.921445 & 1.0 & 4.636364 & 255.0 & 0.89 & 36.10 & 0.57 \\
\hline & 3 & 0.45 & 0.70080745 & 3.0 & 5 & 180.0 & 0.55 & 27.71 & \\
\hline & 4 & 0.40 & 1.1066961 & 3.0 & 4.0701756 & 232.0 & 1.29 & 39.95 & 2.78 \\
\hline & 5 & 0.43 & 0.966462 & 1.0 & 3.620690 & 105.0 & 0.71 & 18.00 & \\
\hline & 6 & 0.52 & 0.689409 & 1.0 & 5.395350 & 60.0 & 0.71 & 26.65 & 0.50 \\
\hline & 7 & 0.06 & 1.078540 & 1.0 & 4.038460 & 210.0 & 1.29 & 28.62 & 0.38 \\
\hline & 8 & & & & & & 0.68 & 42.04 & \\
\hline & 9 & 0.43 & 0.863922 & 1.0 & 4.375000 & 176.0 & 0.79 & 27.00 & 0.75 \\
\hline & 10 & 0.75 & 0.976868 & 1.0 & 3.677420 & 114.0 & 1.50 & 46.20 & 0.37 \\
\hline & $\begin{array}{l}11 \\
12\end{array}$ & 0.11 & 0.864444 & 1.0 & 3.720000 & 93.0 & 0.45 & 36.05 & \\
\hline \multirow[t]{12}{*}{ SST } & 1 & 0.20 & 1.208620 & 3.0 & 3.625000 & 174.0 & 0.73 & 43.88 & \\
\hline & 2 & 0.08 & 0.969942 & 1.0 & 4.454546 & 245.0 & 0.67 & 13.97 & 0.23 \\
\hline & 3 & 0.13 & 1.245880 & 2.0 & 3.250000 & 117.0 & 0.92 & 23.69 & \\
\hline & 4 & 0.17 & 1.489783 & 2.0 & 3.280702 & 187.0 & 1.08 & 20.21 & \\
\hline & 5 & 0.06 & 1.200250 & 2.0 & 3.037040 & 82.0 & 1.64 & 12.00 & \\
\hline & 6 & 0.26 & 0.761979 & 3.0 & 4.976740 & 53.0 & 1.44 & 25.27 & 0.50 \\
\hline & 7 & 0.11 & 1.704064 & 2.0 & 2.877551 & 50.0 & 1.09 & 24.98 & \\
\hline & 8 & 0.22 & 0.898995 & 3.0 & 5.125000 & 369.0 & 1.20 & 57.57 & 0.60 \\
\hline & 9 & 0.09 & 1.445772 & 3.0 & 2.914286 & 102.0 & 1.78 & 20.25 & 0.50 \\
\hline & 10 & 0.50 & 1.3592209 & 2.0 & 2.4444444 & 44.0 & 0.67 & 14.00 & 0.56 \\
\hline & 11 & 0.18 & 1.228485 & 3.0 & 3.1290324 & 97.0 & 0.17 & 22.05 & 0.73 \\
\hline & 12 & 0.11 & 0.496585 & 1.0 & 6.424240 & 212.0 & 1.46 & 56.97 & 0.07 \\
\hline \multirow[t]{12}{*}{ CMS } & 1 & 0.19 & 1.103520 & 2.0 & 3.875000 & 186.0 & 0.58 & 51.62 & 1.21 \\
\hline & 2 & 0.36 & 0.555087 & 1.0 & 7.036364 & 387.0 & 1.14 & 57.57 & 0.86 \\
\hline & 3 & 0.77 & 0.89306432 & 2.0 & 4.1388888 & 149.0 & 1.25 & 38.00 & 1.00 \\
\hline & 4 & 1.25 & 1.195505 & 3.0 & 3.842105 & 219.0 & 0.77 & 56.75 & 6.25 \\
\hline & 5 & 0.08 & 1.360210 & 1.0 & 2.862070 & 83.0 & 0.83 & 5.76 & 1.27 \\
\hline & 6 & 0.12 & 0.904850 & 2.0 & 4.348840 & 50.0 & 0.91 & 24.86 & 0.50 \\
\hline & 7 & 0.23 & 1.385440 & 2.0 & 3.365380 & 175.0 & 0.65 & 10.80 & 1.54 \\
\hline & 8 & 0.47 & 0.839627 & 3.0 & 5.416670 & 390.0 & 0.63 & 42.32 & 2.00 \\
\hline & 9 & 0.34 & 0.963061 & 2.0 & 4.0500002 & 162.0 & 0.79 & 10.80 & 0.19 \\
\hline & 10 & 0.17 & 0.976868 & 1.0 & 3.677420 & 114.0 & 0.48 & 42.00 & 0.37 \\
\hline & 11 & 0.19 & 0.864444 & 1.0 & 3.720000 & 93.0 & 0.45 & 32.55 & 0.94 \\
\hline & 12 & 0.50 & 0.555364 & 1.0 & 6.230770 & 243.0 & 1.64 & 58.59 & 2.14 \\
\hline \multirow[t]{10}{*}{ DSR } & 1 & & & & & & & & \\
\hline & 2 & & & & & & & & \\
\hline & 3 & 0.21 & 1.035430 & 1.0 & 3.173910 & 73.0 & 1.07 & 26.19 & 1.60 \\
\hline & 4 & 0.27 & 0.90925741 & 1.0 & 4.7368422 & 270.0 & 0.72 & 23.27 & \\
\hline & 5 & 0.35 & 0.758781 & & 4.222220 & 114.0 & 1.17 & 32.22 & \\
\hline & 6 & 0.61 & 1.284840 & 1.0 & 2.791667 & 67.0 & 0.85 & 21.83 & 0.83 \\
\hline & 7 & 0.75 & 1.085410 & 1.0 & 4.019230 & 209.0 & 0.84 & 26.46 & 0.96 \\
\hline & 8 & 0.50 & 0.641831 & 2.0 & 6.777780 & 488.0 & 1.52 & 51.30 & 4.00 \\
\hline & 9 & 0.40 & 0.863922 & 1.0 & 4.4000001 & 176.0 & 0.79 & 21.60 & 0.50 \\
\hline & 10 & 0.87 & 1.0496821 & 1.0 & 3.24 & 81.0 & 1.59 & 16.45 & 4.44 \\
\hline
\end{tabular}


Bai, L., \& Nasu, S. / Asian Journal of Environment-Behaviour Studies (ajE-Bs), 4(14) Sep / Dec 2019 (pp.1-20)

\begin{tabular}{|c|c|c|c|c|c|c|c|c|c|}
\hline $\begin{array}{r}\text { Common } \\
\text { space }\end{array}$ & NHID & $\begin{array}{l}\text { ARE, } \\
\mathrm{m}^{2} / \mathrm{p}\end{array}$ & INT & CNN & MDP & TDP & VHR & PRX & OCP, $\%$ \\
\hline & $\begin{array}{l}11 \\
12\end{array}$ & 0.54 & 0.603339 & 1.0 & 6.631580 & 81.0 & 0.51 & 20.30 & \\
\hline
\end{tabular}

Note; NHID nursing home ID; ENH, entrance hall; DRM, dining room; PTR, physical training room; MPR, multiple purpose room; SST, service station; CMS, community space; DSR, daily service room; LVS, living area.

(Source: Created by author)

\subsection{Common Space Occupancy Regression Model}

Table 6 is the spatial metrics considered in this research. In multiple linear regression analysis, they are independent variables (IVs), while the space occupancy (OCP) is the dependent variable (DV).

Table 6: Spatial metrics considered for space occupancy

\begin{tabular}{|c|c|c|c|c|c|}
\hline \multicolumn{3}{|c|}{ Spatial metrics } & Variables & Explanation & Equation definition \\
\hline $\begin{array}{l}\text { The } \\
\text { depend } \\
\text { ent } \\
\text { variable } \\
\text {, DV }\end{array}$ & \multicolumn{2}{|c|}{ Space occupancy, OCP } & $\mathrm{OCP}$ & $\begin{array}{l}\text { The space } \\
\text { occupancy rate } \\
\text { for all staying } \\
\text { activity }\end{array}$ & $\begin{array}{l}\text { OCP }= \\
\left(\mathbb{N}\left(\mathrm{NUM}^{\star} \mathrm{TIM}\right)\right) /(\text { Total } \\
\text { observed residents*600) } \\
\text { Where NUM is the number } \\
\text { of people who are staying } \\
\text { in the commonplace, and } \\
\text { TIM is the time interval of } \\
\text { the observation. }\end{array}$ \\
\hline \multirow[t]{7}{*}{$\begin{array}{l}\text { Indepen } \\
\text { dent } \\
\text { variable } \\
\text { s, IVs }\end{array}$} & \multirow[t]{4}{*}{$\begin{array}{l}\text { Space } \\
\text { syntax } \\
\text { metrics }\end{array}$} & $\begin{array}{l}\text { Spatial } \\
\text { integration }\end{array}$ & INT & $\begin{array}{l}\text { The spatial } \\
\text { integration to all } \\
\text { spaces in a } \\
\text { nursing home. }\end{array}$ & $\begin{array}{l}\text { INT = 1/RRA } \\
\text { RRA is Real Relative } \\
\text { Asymmetry. }\end{array}$ \\
\hline & & $\begin{array}{l}\text { Spatial } \\
\text { connectivity }\end{array}$ & CNN & $\begin{array}{l}\text { The direct } \\
\text { connection of } \\
\text { specified space } \\
\text { to its } \\
\text { surrounding } \\
\text { spaces }\end{array}$ & $\begin{array}{l}\text { CNN = } \mathrm{C} \\
\text { Where } \mathrm{c} \text { is the connection } \\
\text { routines with surrounding } \\
\text { spaces. }\end{array}$ \\
\hline & & $\begin{array}{l}\text { Spatial } \\
\text { mean } \\
\text { depth }\end{array}$ & MDP & $\begin{array}{l}\text { The mean } \\
\text { depth from all } \\
\text { other space. }\end{array}$ & $\begin{array}{l}\mathrm{MDP}=\left(\sum\left(D k^{*} k\right)\right) /(n-1) \\
\text { Where } D \text { is the depth from } \\
\text { a space unit, } n \text { is total } \\
\text { space unit number, } k=1 \sim n \text {. }\end{array}$ \\
\hline & & $\begin{array}{l}\text { Spatial total } \\
\text { depth }\end{array}$ & TDP & $\begin{array}{l}\text { The total depth } \\
\text { from all other } \\
\text { space. }\end{array}$ & $\begin{array}{l}\text { TDP }=\sum\left(D k^{*} k\right) \\
\text { Where } D \text { is the depth from } \\
\text { a space unit, } n \text { is total } \\
\text { space unit number, } k=1 \sim n \text {. }\end{array}$ \\
\hline & \multirow[t]{3}{*}{$\begin{array}{l}\text { Geometrical } \\
\text { factors }\end{array}$} & Area size & ARE & $\begin{array}{l}\text { The space area } \\
\text { size per } \\
\text { resident, } \mathrm{m} 2 / \mathrm{a}\end{array}$ & Evaluated by floor plan. \\
\hline & & $\begin{array}{l}\text { Vertical to } \\
\text { horizontal } \\
\text { ratio }\end{array}$ & VHR & $\begin{array}{l}\text { The ratio of } \\
\text { vertical length } \\
\text { to horizontal. }\end{array}$ & $\begin{array}{l}\text { VHR = (The length in the } \\
\text { vertical direction)/(The } \\
\text { length in the horizontal } \\
\text { direction). }\end{array}$ \\
\hline & & Proximity & PRX & $\begin{array}{l}\text { The average } \\
\text { distance(PRX, } \\
\mathrm{m}) \text { from the }\end{array}$ & $\begin{array}{l}\mathrm{PRX}=\left(\sum(\mathrm{Dis})\right) /(\text { Number of } \\
\text { living zones) } \\
\text { Where Dis is the distance }\end{array}$ \\
\hline
\end{tabular}


Bai, L., \& Nasu, S. / Asian Journal of Environment-Behaviour Studies (ajE-Bs), 4(14) Sep / Dec 2019 (pp.1-20)

\begin{tabular}{|c|c|c|c|}
\hline Spatial metrics & Variables & Explanation & Equation definition \\
\hline & & $\begin{array}{l}\text { care unit to a } \\
\text { common } \\
\text { facility, } m \text {. }\end{array}$ & $\begin{array}{l}\text { from a care unit zone to } \\
\text { common space. }\end{array}$ \\
\hline
\end{tabular}

(Source: Created by author)

The different common facilities (such as the lobby, community space, physical training room) in a nursing home can be used for various purposes and affects the occupancy. However, as the first stage of research, here we don't discriminate the different common facilities and take all of them as one general common facility type to analyze the association between occupancy and spatial configuration. Besides, the residents with different genders, age, and health conditions can have different utilization purpose and behavior in common facilities, we won't detail it in this research.

(1) Data Correlation Analysis

First, we analyze the data correlation between occupancy and spatial configuration. Table 7 is the result.

Table 7: Data correlation between space occupancy and spatial configuration metrics

\begin{tabular}{|c|c|c|c|c|c|c|c|c|c|}
\hline & & OCP & INT & CNN & MDP & TDP & ARE & VHR & PRX \\
\hline \multirow[t]{3}{*}{$\mathrm{OCP}$} & $\begin{array}{l}\text { Pearson } \\
\text { Correlation }\end{array}$ & 1 & $.422^{* *}$ & $.396^{* *}$ & $-.326^{* *}$ & $\begin{array}{r}- \\
0.145\end{array}$ & $.473^{*+}$ & 0.027 & -0.163 \\
\hline & Sig. (2-tailed) & & 0.001 & 0.001 & 0.010 & 0.262 & 0.000 & 0.836 & 0.206 \\
\hline & $\mathrm{N}$ & 62 & 62 & 62 & 62 & 62 & 62 & 62 & 62 \\
\hline \multirow[t]{3}{*}{ INT } & $\begin{array}{l}\text { Pearson } \\
\text { Correlation }\end{array}$ & $.422^{* *}$ & 1 & $.435^{* *}$ & $-.857^{\star *}$ & $409^{-}$ & 0.034 & 0.003 & $-.385^{* *}$ \\
\hline & Sig. (2-tailed) & 0.001 & & 0.000 & 0.000 & 0.000 & 0.770 & 0.982 & 0.001 \\
\hline & $\mathrm{N}$ & 62 & 76 & 75 & 76 & 76 & 76 & 76 & 76 \\
\hline \multirow[t]{3}{*}{ CNN } & $\begin{array}{l}\text { Pearson } \\
\text { Correlation }\end{array}$ & $.396^{* *}$ & $.435^{* *}$ & 1 & $-.263^{*}$ & 0.013 & 0.169 & 0.029 & 0.027 \\
\hline & Sig. (2-tailed) & 0.001 & 0.000 & & 0.023 & 0.911 & 0.148 & 0.807 & 0.821 \\
\hline & $\mathrm{N}$ & 62 & 75 & 75 & 75 & 75 & 75 & 75 & 75 \\
\hline \multirow[t]{3}{*}{ MDP } & $\begin{array}{l}\text { Pearson } \\
\text { Correlation }\end{array}$ & $\begin{array}{r}- \\
.326^{*+}\end{array}$ & $-.857^{\star *}$ & $-.263^{*}$ & 1 & $.658^{* *}$ & 0.071 & 0.049 & $.481^{\text {t* }}$ \\
\hline & Sig. (2-tailed) & 0.010 & 0.000 & 0.023 & & 0.000 & 0.544 & 0.676 & 0.000 \\
\hline & $\mathrm{N}$ & 62 & 76 & 75 & 76 & 76 & 76 & 76 & 76 \\
\hline \multirow[t]{3}{*}{ TDP } & $\begin{array}{l}\text { Pearson } \\
\text { Correlation }\end{array}$ & 0.145 & $-.409^{* *}$ & -0.013 & $.658^{* *}$ & 1 & $0.090^{-}$ & 0.013 & $.566^{* *}$ \\
\hline & Sig. (2-tailed) & 0.262 & 0.000 & 0.911 & 0.000 & & 0.437 & 0.912 & 0.000 \\
\hline & $\mathrm{N}$ & 62 & 76 & 75 & 76 & 76 & 76 & 76 & 76 \\
\hline \multirow[t]{3}{*}{ ARE } & $\begin{array}{l}\text { Pearson } \\
\text { Correlation }\end{array}$ & $.473^{* *}$ & 0.034 & 0.169 & -0.071 & $0.090^{-}$ & 1 & 0.072 & -0.084 \\
\hline & Sig. (2-tailed) & 0.000 & 0.770 & 0.148 & 0.544 & 0.437 & & 0.538 & 0.470 \\
\hline & $\mathrm{N}$ & 62 & 76 & 75 & 76 & 76 & 76 & 76 & 76 \\
\hline \multirow[t]{3}{*}{ VHR } & $\begin{array}{l}\text { Pearson } \\
\text { Correlation }\end{array}$ & 0.027 & -0.003 & 0.029 & 0.049 & 0.013 & 0.072 & 1 & 0.031 \\
\hline & Sig. (2-tailed) & 0.836 & 0.982 & 0.807 & 0.676 & 0.912 & 0.538 & & 0.789 \\
\hline & $\mathrm{N}$ & 62 & 76 & 75 & 76 & 76 & 76 & 77 & 77 \\
\hline PRX & $\begin{array}{l}\text { Pearson } \\
\text { Correlation }\end{array}$ & 0.163 & $-.385^{\star *}$ & 0.027 & $.481^{* *}$ & $.566^{* *}$ & 0.084 & 0.031 & 1 \\
\hline
\end{tabular}


Bai, L., \& Nasu, S. / Asian Journal of Environment-Behaviour Studies (ajE-Bs), 4(14) Sep / Dec 2019 (pp.1-20)

\begin{tabular}{lr|r|r|r|r|r|r|r} 
Sig. (2-tailed) & 0.206 & 0.001 & 0.821 & 0.000 & 0.000 & 0.470 & 0.789 & \\
\hline $\mathrm{N}$ & 62 & 76 & 75 & 76 & 76 & 76 & 77 & 77 \\
\hline
\end{tabular}

*. Correlation is significant at the 0.05 level (2-tailed).

**. Correlation is significant at the 0.01 level (2-tailed).

(Source: Created by author)

Table 7 shows that the space occupancy(OCP) is significantly correlated with spatial integration(INT), spatial connectivity(CNN), spatial mean depth(MDP), and area size(ARE) by $r(62)=0.422, p($ Sig. $)<0.05 ; r(62)=0.396, p<0.05 ; r(62)=-0.326, p<0.05 ; \quad r(62)=-0.473$, $p<0.05$ respectively. There is no significant correlation between occupancy(OCP) and spatial total depth(TDP), space vertical to the horizontal ratio(VHR), space proximity(PRX) because the $p$ (Sig.) $>=0.05$ for all these 3 spatial metrics.

However, among the four spatial metrics (INT, CNN, ARE, MDP) which significantly correlated with occupancy, the MDP is highly correlated with others by $(r(76)=-0.857$, $p<0.05)$ for INT, and $(r(75)=-0.263, p<0.05)$ for $C N N$. It means that multicollinearity exists among MDP and other metrics, MDP should be removed from multiple linear regression analysis.

Next, we use the coefficient of determination(R-square) to sort the effect of each spatial metrics (IVs) to occupancy. Figure 8 shows the result of changes in R-square in linear regression by adding each IV.

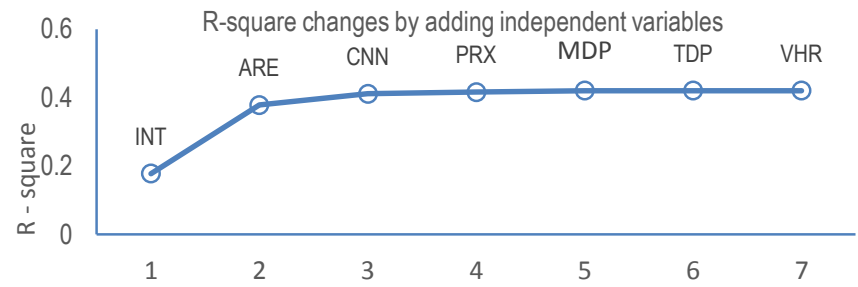

Figure 8: Change of R-square with different spatial metrics (IVs)

(Source: Created by author)

The result suggests that the three spatial metrics INT, ARE, CNN are a proper IVs combination for space occupancy regression because the R-square doesn't increase significantly after adding CNN.

(2) Occupancy Multiple Linear Regression Model

Table 8 is the result.

Table 8: Multiple linear regression results

Model Summary a

\begin{tabular}{cc|c|c|c}
\hline Model & $\mathrm{R}$ & R Square & Adjusted R Square & $\begin{array}{c}\text { Std. Err. of the } \\
\text { Estimate }\end{array}$ \\
\hline 1 & $.641^{\mathrm{b}}$ & 0.411 & 0.381 & 2.84085 \\
\hline
\end{tabular}

a. Predictors: (Constant), INT, ARE, CNN

b. Dependent Variable: OCP

ANOVA a 
Bai, L., \& Nasu, S. / Asian Journal of Environment-Behaviour Studies (ajE-Bs), 4(14) Sep / Dec 2019 (pp.1-20)

\begin{tabular}{ccc|c|c|c|c}
\hline & Model & Sum of Squares & df & Mean Square & $\mathrm{F}$ & Sig. \\
\hline \multirow{2}{*}{1} & Regression & 327.274 & 3 & 109.091 & 13.517 & $.000^{\mathrm{b}}$ \\
\cline { 2 - 7 } & Residual & 468.084 & 58 & 8.070 & & \\
\cline { 2 - 7 } & Total & 795.358 & 61 & & & \\
\hline
\end{tabular}

a. Dependent Variable: OCP

b. Predictors: (Constant), INT, ARE, CNN

Coefficients a

\begin{tabular}{|c|c|c|c|c|c|c|c|c|}
\hline & \multirow[b]{2}{*}{ Model } & \multicolumn{2}{|c|}{$\begin{array}{l}\text { Unstandardized } \\
\text { Coefficients }\end{array}$} & \multirow{2}{*}{ 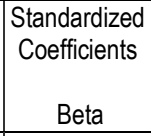 } & \multirow[t]{2}{*}{$t$} & \multirow[t]{2}{*}{ Sig.(p) } & \multicolumn{2}{|c|}{$\begin{array}{l}95.0 \% \text { Confidence } \\
\text { Interval for B }\end{array}$} \\
\hline & & B & Std. Error & & & & $\begin{array}{l}\text { Lower } \\
\text { Bound }\end{array}$ & $\begin{array}{l}\text { Upper } \\
\text { Bound }\end{array}$ \\
\hline 1 & (Constant) & -4.206 & 1.441 & & $\begin{array}{c}- \\
2.920\end{array}$ & 0.005 & -7.090 & -1.322 \\
\hline & INT & 3.752 & 1.443 & 0.297 & 2.601 & 0.012 & 0.864 & 6.640 \\
\hline & ARE & 3.301 & 0.777 & 0.431 & 4.249 & 0.000 & 1.746 & 4.855 \\
\hline & CNN & 0.506 & 0.280 & 0.208 & 1.809 & 0.076 & -0.054 & 1.066 \\
\hline
\end{tabular}

a. Dependent Variable: OCP

(Source: Created by author)

Table 8, the model summary, shows that the three spatial metrics of integration INT, area size ARE, and connectivity CNN are significantly related to space occupancy OCP by $F(3,58)$ $=13.517, p=0.000<0.001$. The multiple regression coefficients $(R)$ is .641 , indicates that approximately(R-square) $41.1 \%$ of the variance of the space occupancy can be predicted by using spatial integration INT, spatial connectivity CNN, and space size ARE.

With the unstandardized coefficients of $B$ in the coefficients table of Table 8, we get the space occupancy OCP regression equation.

(3) Coefficients of Each Spatial Metrics

$$
\begin{aligned}
\mathrm{OCP}(\%) & =f(I N T, C N N, A R E) \\
& =3.752 * \mathrm{INT}+3.301 * \mathrm{ARE}+0.506 * \mathrm{CNN}-4.206
\end{aligned}
$$

Spatial integration, INT - It is 3.752, indicates for every unit increase in spatial integration, the space occupancy can increase $3.75 \%$ in case the other spatial metrics(CNN, ARE) are constant.

The space area, ARE - It is 3.301 , indicates every increase of a square meter per resident in space relates to $3.30 \%$ increase of occupancy when other spatial metrics are constant.

Spatial connectivity, CNN - It is 0.506 , indicates every unit increase in spatial connectivity will relate to increasing of space occupancy by $0.51 \%$ in case other spatial metrics(INT, ARE) are constant.

(4) t-Statistics of Each Coefficient

The t-statistics(t column) and associated 2-tailed p-values(Sig. column) in coefficient table of Table 8 shows that the Sig.(p) of coefficient of INT, ARE, CNN, and intercept are almost all less than 0.05 (0.07 for $\mathrm{CNN}$ ), they differ significantly from 0 at the 0.05 alpha level Note 3

). Therefore, we can conclude that within the surveyed common facilities occupancy data, the spatial integration, area size per resident, and spatial connectivity are three significant spatial 
metrics to space occupancy in Japanese nursing home.

(5) The Association between Space Occupancy and Space Syntax Metrics in Japanese Nursing Home

This space occupancy regression model also shows that except the spatial integration and spatial connectivity metrics from Space syntax theory, the area size per resident is also significant to residents' space occupancy. It means that the method and application of SS theory alone are not complete for elderly residents in Japanese nursing home. But together with the area size per resident, the spatial integration and connectivity from SS theory are significantly related to space occupancy in Japanese nursing home.

\section{Conclusion}

There are several factors may affect the occupancy of common space in the nursing home. They can be social and cultural aspects, administrative environment, and space configuration. By only taking into account the space configuration, this study explored the association between space occupancy and spatial configuration in Japanese nursing home to contribute to the common facility spatial design for better space occupancy. The spatial configuration in this paper includes space geometric metrics of area size per residents, shape, distance to living space, and the spatial metrics measured by Space syntax theory.

The multiple linear regression analysis reveals that the spatial integration, area size per resident, and spatial connectivity are three significant metrics to the common facility space occupancy in Japanese nursing home.

The results disclose that the increase of links to the common facilities, designing the space with higher spatial integration, and having more substantial area size per resident are three factors to raise common facility space occupancy in Japanese nursing home.

Also, the analysis in this article confirms that the method and application of Space syntax theory alone are not complete to residents in Japanese nursing homes.

However, we base the above conclusion on the occupancy data surveyed in twelve nursing homes. The coefficient value and even the linear regression equation may differ if there is a significant difference from other nursing homes. Further, the conclusion in this article doesn't consider the specific behavior of residents in different common facilities by different age, gender, and health conditions.

\section{Acknowledgment}

This work is subsidized by the Tokyo Institute of Technology TRA program, data, and the conclusion in this article is partly from the author's Ph. D. dissertation.

\section{Note}

1) Ministry of Health, Labor and Welfare (Sep. 28, 2009), http:/www.mhlw.go.jp/topics/kaigo/kaigi/010928/siryo51.html (accessed May 25, 2018).

2) Standardized Beta Coefficient, http://www.statisticshowto.com/standardized-beta-coefficient (accessed June 9 , 
Bai, L., \& Nasu, S. / Asian Journal of Environment-Behaviour Studies (ajE-Bs), 4(14) Sep / Dec 2019 (pp.1-20)

2018)

3) Definition of nursing care level. http://www.rikubetsu.or.jp/kaigo/hoken6.html (accessed Jan. 13, 2019).

\section{References}

Bai Lin, Nasu Satoshi (2018), The transition of common space area in Japanese intensive care home fro the elderly since 1978. J. Archit. Plann., AlJ, 83(749), pp. 1183-1192.

Brown E. (1986) Continuity and change in the urban house. Comparative Studies in Society and History, 28(3), pp.558590.

Byoung-Suk Kweon, William C. Sullivan, Angela R. Wiley(1998), Green Common Spaces and the Social Integration of Inner-City Older Adults, Environment and Behavior, 30(6), pp.832-858.

Chaeshin Y. (2009), Alternative geometry for space syntax. Proceedings of the 7th International Space Syntax Symposium, Edited by Daniel Koch, Lars Marcus, and Jesper Steen, Stockholm: KTH. pp. 133:2-133:12.

Candace L. Kemp, Mary M. Ball, Carole Hollingsworth, Molly M. Perkins (2012), Strangers and Friends: Residents' Social Careers in Assisted Living. The Journals of Gerontology: Series B, 67(4), pp.491-502.

Congsi Hou, Gesine Marquardt (2015), spatial layout and spontaneous behavior for people with dementia: A study of adult day-care centers. Proceedings of the 10th international Space Syntax Symposium, pp. 19:1-19:15.

Dettlaff, W. (2014), Space syntax analysis - methodology of understanding the space. Ph.D. Interdisciplinary Journal, Vol.1, pp. 283-291.

Dursun P. and Saglamer G. (2003), Spatial Analysis of Different Home Environments in the City of Trabzon, Proceedings of 4th International Space Syntax Symposium, University College London, 17-19. June 2003, vol. II, pp. 54.1-54.18.

Hillier B., Hanson J. (1984) The Social Logic of Space, Cambridge University Press, Cambridge.

Hillier Bill, Alasdair Turner, Tao Yang, Hoon-Tae Park(2007), Metric and topo-geometric properties of urban street networks, proceedings, 6th International Space Syntax Symposium Istanbul, pp. 001.01-001.21.

IBM Corp. Released in 2016. IBM SPSS Statistics for Windows, Version 24.0. Armonk, NY: IBM Corp.

Inoue Makoto (1990), A study on common facility planning for the paid nursing home, Shimizu Corporation Research Report, 51, p83-94.

Ishibashi Youjiro, Ishii Satoshi, Miura Ken(2015), Analysis of utilization and related factors of common living space in unit care nursing homes. Welfare Indicator, 62(11), pp.32-38.

Kang S(2012). Spatial analysis and application study on medical and welfare facilities - a case study of space syntax and isovist, Kobe University Ph.D. dissertation.

Kanki Yumi, Takada Mitsuo, Miura Ken(2005a), Study on the residents' space-use and behavior at common spaces 
inside their units at the assisted living with private rooms and units - Actual conditions of residents' space-use and behavior at the assisted living with private rooms and units, Part 1 -, J. Archit. Plann., AIJ, No. 592, pp. 65-70.

Kanki Yumi, Takada Mitsuo, Miura Ken(2005b), 5029 Study on the Residents' Space-Use and Behavior outside their Units at the Assisted Living with Private Rooms. Architectural Institute of Japan, Planning, Vol.45, pp.113-116.

Kato Yusuke (2007), Environmental Behavioral Study on Space Creation in Elderly Facilities, University of Osaka, Ph.D. dissertation.

MHLW (2015), General Affairs Division, Planning Legal Affairs Section, Gerontological Agency, Ministry of Health, Labour and Welfare. Elderly care for 2015 - Establishing care to support the dignity of elderly people.

MHLW, Ministry of Health, Labour and Welfare (2017). The 2016 year nursing care service facility · Business survey.

Michael J. Dawes, Michael J. Ostwald (2013), Precise locations in space: An alternative approach to space syntax analysis using intersection points. Architecture Research, 3(1), pp.1-11.

Mori Shiho, Inoue Yukiko, Taniguchi Gen(2003), A study on planning based on the care system in the unit-type nursing home, J. Archit. Plann, AlJ, No.572, pp.41 -47.

Mori Shiho (2004), A study on elderly living facilities from the viewpoint of living improvement, Nagoya University, Ph.D. dissertation.

Murakami S.(2011), The relation between environment and living in the nursing home, Proceedings of Architecture Institute of Japan, E-1.Architectural Planning I.

Park N. S. (2009), The relationships of social engagement to the psychological well-being of older adults in assisted living facilities. Journal of Applied Gerontology, 28, pp. 461-481.

Peiman A. Behbahani, etc. (2014), Comparing The Properties of Different Space Syntax Techniques for Analysing Interiors, Across Architectural Research through to Practice: 48th International Conference of the Architectural Science Association. (C2014. The Architectural Science Association \& Genova University Press, pp.683-694.

Peponis J. and Wineman, J.(2002), Spatial Structure of Environment and Behavior. In: R. Bechtel and A. Churchman (Ed.), Handbook of environmental psychology. John Wiley and Sons, Inc. New York.

Saif H. (2012), Space Syntax in Healthcare Facilities Research: A Review, HERD, 5(4), pp. 98-117.

Takano Y(2012) A study of districts properties applying topological and geometrical characteristics of street patterns. Journal of City Planning Institute of Japan, 46(3), pp.661-666.

Varoudis, T(2013), Space Syntax Angular Betweenness Centrality Revisited. Proceedings of the 9th International Space Syntax Symposium, pp.057:7. 